\title{
Simulation-based Design of a Shadow Shield for the MIND Backpack System
}

D. Lee

B. Bucher

K. Krebs

E. Seabury

J. Wharton

July 2019

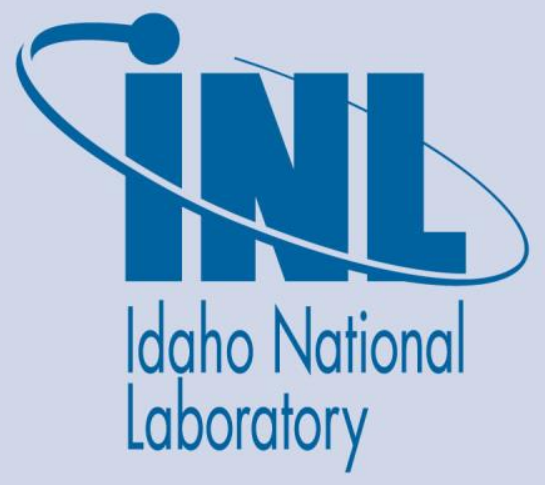

The INL is a U.S. Department of Energy National Laboratory operated by Battelle Energy Alliance 


\section{DISCLAIMER}

This information was prepared as an account of work sponsored by an agency of the U.S. Government. Neither the U.S. Government nor any agency thereof, nor any of their employees, makes any warranty, expressed or implied, or assumes any legal liability or responsibility for the accuracy, completeness, or usefulness, of any information, apparatus, product, or process disclosed, or represents that its use would not infringe privately owned rights. References herein to any specific commercial product, process, or service by trade name, trade mark, manufacturer, or otherwise, does not necessarily constitute or imply its endorsement, recommendation, or favoring by the U.S. Government or any agency thereof. The views and opinions of authors expressed herein do not necessarily state or reflect those of the U.S. Government or any agency thereof. 


\title{
Simulation-based Design of a Shadow Shield for the MIND Backpack System
}

\author{
D. Lee \\ B. Bucher \\ K. Krebs \\ E. Seabury \\ J. Wharton \\ June 2019 \\ Idaho National Laboratory \\ Nuclear Nonproliferation Division \\ Idaho Falls, Idaho 83415
}

http://www.inl.gov

Prepared for the

U.S. Department of Energy

Office of National Nuclear Security Administration

Under DOE Idaho Operations Office

Contract DE-AC07-05ID14517 



\begin{abstract}
Modeling and simulation is a cost- and time-saving method to study conceptual designs of radiation detection systems. MCNP radiation transport code has been an indispensable tool in development of radiation detection systems, and the PINS systems have also utilized MCNP modeling and simulation in the system development. MCNP models of the PINS systems have been used to understand detector responses and to fill the gap in experimental data. Recently, the MIND backpack system was announced to be developed, and its prototype design was required to conduct laboratory tests and demonstrations. A shadow shield is the component to be designed by Idaho National Laboratory in order to maximize the performance of a backpack system while meeting the sponsor's requirements. MCNP modeling and simulation was utilized to find the best specification of a shadow shield. This study was performed to down-select a shadow shield design for the MIND system. A total of 24 designs for a shadow shield were identified to build MCNP models, and their simulation results were used to prioritize each design. As a quantitative performance metric, an equation of Figure-of-Merit was introduced in the decision making analysis. In addition, the Analytic Hierarchy Process was adopted to prioritize and recommend best performing shadow shield designs.
\end{abstract}




\section{CONTENTS}

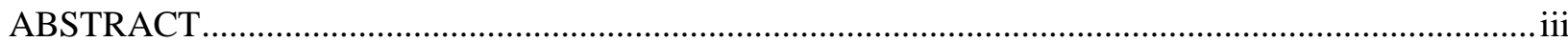

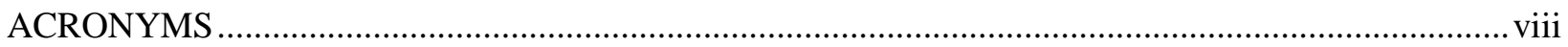

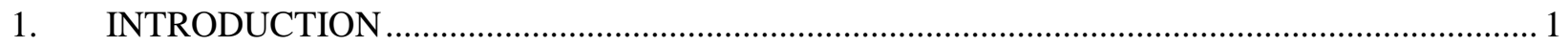

2. EXPERIMENTAL CAMPAIGN AND MCNP MODEL VALIDATION ...................................... 1

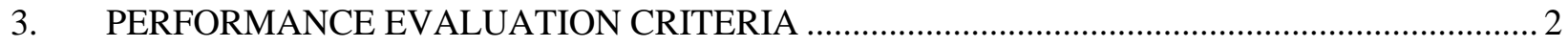

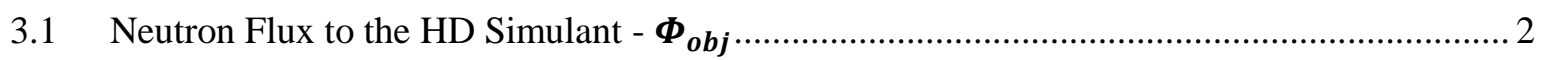

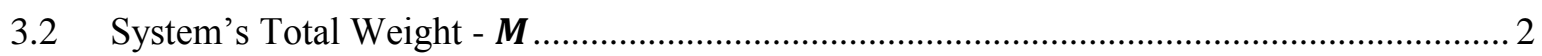

3.3 Neutron Flux to the HPGe Simulant $-\boldsymbol{\Phi}_{\boldsymbol{d}} \boldsymbol{t e}$

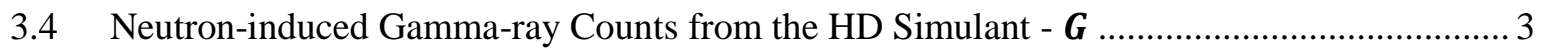

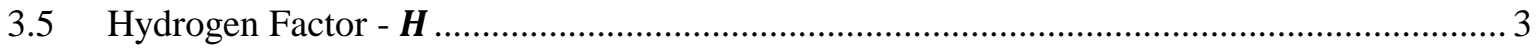

4. PERFORMANCE EVALUATION OF SHADOW SHIELD MOCKUPS.................................... 3

5. EXPANDED STUDY WITH REFINED SHADOW SHIELD DESIGNS .................................... 5

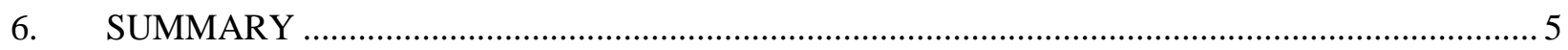

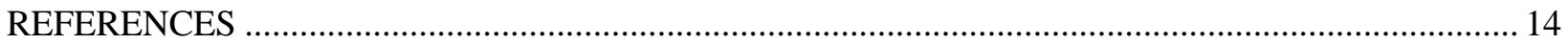

\section{FIGURES}

Figure 1. MCNP models of six unique shadow shield configurations ................................................. 6

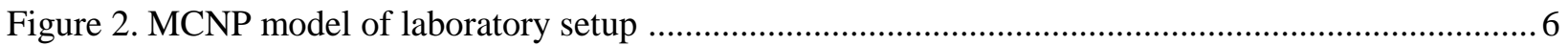

Figure 3. Comparison between simulated and experimental gamma-ray spectra for the

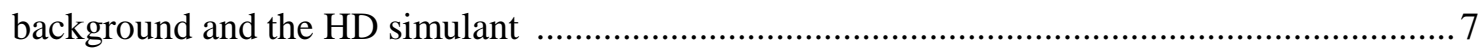

Figure 4. A simple hierarchy to select the best shadow shield design in AHP method ............................ 7

Figure 5. The calculated scores of the six mockups by AHP and FoM methods ...................................... 8

Figure 6. The calculated scores of the 24 shadow shield configurations by AHP and FoM methods .......... 8

Figure 7. Behaviors of the four criteria values as functions of shadow shield total length ....................... 9

Figure 8. Behaviors of the five criteria values are shown as function of the ratio of HDPE-to-

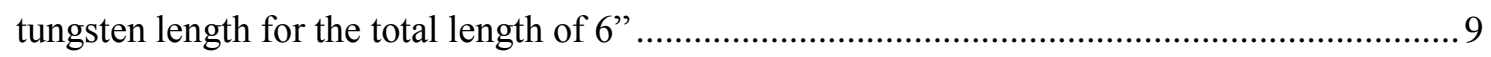

Figure 9. The final shadow shield design recommended by the simulation-based study ........................ 10 


\section{TABLES}

Table 1. Simulated neutron energy distributions inside the HD simulant volume $\left(\Phi_{\mathrm{obj}}\right)$ and the HPGe detector volume $\left(\Phi_{\text {det }}\right)$ from the MCNP simulation results ......................................... 11

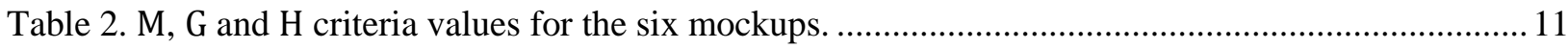

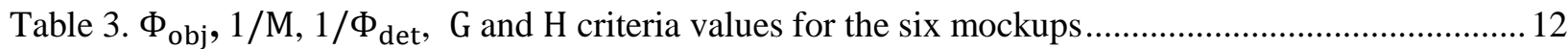

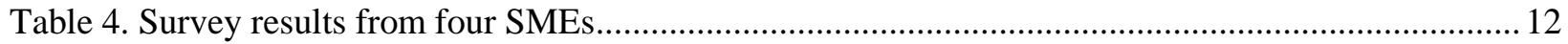

Table 5. The pairwise comparison matrix from the SME survey results ................................................ 12

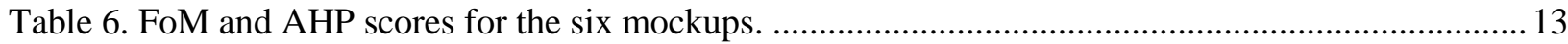

Table 7. FoM and AHP scores for the all 24 configurations evaluated in the expanded study ................. 13 


\section{ACRONYMS}

$\begin{array}{ll}\text { AHP } & \text { Analytic hierarchy process } \\ \text { D-D } & \text { Deuterium-deuterium } \\ \text { FoM } & \text { Figure-of-Merit } \\ \text { GB } & \text { Sarin nerve agent } \\ \text { GEB } & \text { Gaussian Energy Broadening } \\ \text { HD } & \text { Sulfur mustard blister agent } \\ \text { HDPE } & \text { High density polyethylene } \\ \text { HPGe } & \text { High purity germanium } \\ \text { INL } & \text { Idaho National Laboratory } \\ \text { L } & \text { Lewisite blister agent } \\ \text { MCNP } & \text { Monte Carlo n-particle } \\ \text { MIND } & \text { Man-portable isotopic non-intrusive detection } \\ \text { PINS } & \text { Portable Isotopic Neutron Spectroscopy } \\ \text { SME } & \text { Subject matter expert } \\ \text { VX } & \text { Nerve agent }\end{array}$




\section{Simulation-based Design of a Shadow Shield for the MIND Backpack System}

\section{INTRODUCTION}

Modeling and simulation is a cost- and time-saving method to study conceptual designs of radiation detection systems. MCNP (Monte Carlo n-Particle) radiation transport code has been an indispensable tool in development of radiation detection systems, and the PINS systems have also utilized MCNP modeling and simulation in the system development. MCNP models of the PINS systems have been used to understand detector responses and to fill the gap in experimental data. Recently, the MIND (Manportable Isotopic Non-intrusive Detection) backpack system was announced to be developed, and its prototype design was required to conduct laboratory tests and demonstrations. When a neutron generator from Thermo Fisher Scientific and a HPGe detector from ORTEC are manufactured for this project, a shadow shield is the component to be designed by Idaho National Laboratory in order to maximize the performance of a backpack system while meeting the sponsor's requirements. It is obvious for us to rely on MCNP modeling and simulation to find the best specification of a shadow shield. A campaign of PINS lab measurements with a few shadow shield mockups has been conducted to validate MCNP results [1], and this follow-up study was performed to down-select a shadow shield design for the MIND system. Several alternative designs for a shadow shield were identified to build MCNP models, and their simulation results were used to prioritize each design. As a quantitative performance metric, an equation of Figure-of-Merit (FoM) was introduced in the decision making analysis. In addition to the FoM, the Analytic Hierarchy Process (AHP) was adopted to prioritize and recommend best performing shadow shield designs [2]].

\section{EXPERIMENTAL CAMPAIGN AND MCNP MODEL VALIDATION}

Six different configurations of shadow shield were tested in the experimental campaign previously [1]. In summary, existing tungsten alloy blocks of three different dimensions were selected: their dimensions (W $\times \mathrm{H} \times \mathrm{L}$ ) are 2-13/16" $\times 2-13 / 16 " \times 3$ " (hereinafter referred to as "M"), 2-13/16" $\times 2-13 / 16 " \times 1-1 / 8$ " (hereinafter referred to as "S") and 4 " $\times 4$ " $\times 2$ " (hereinafter referred to as "L"). Two different shapes of high density polyethylene (HDPE) blocks were used as a neutron moderator: truncated wedge (hereinafter referred to as "W") and truncated pyramid (hereinafter referred to as "P"). An existing HDPE pyramid block was used to build the configuration P-M and P-S while new HDPE blocks were fabricated to build the configurations P-L, W-S, W-M and W-L as shown in Figure 1. A P385 D-D neutron generator (operated at $130 \mathrm{kV}$ and $70 \mu \mathrm{A}$ ) and a nitrogen cooled HPGe detector (system ID P09) were used in a PINS setup assembled for this study. All shadow shields were oriented to have the HDPE block see the generator and the tungsten blocks face the HPGe detector.

These six unique shadow shield mockups were tested with four PINS simulants and background. Figure 2 shows the experimental PINS setup with a shadow shield mockup in the PINS laboratory. Four different PINS simulant cylinders were used in the laboratory measurements: HD, VX, GB and L simulants. As usual, a background spectrum was collected for 1000-second as the first measurement of each day, and a 
spectrum for each simulant was collected for 3000-second one after another. This data collection routine was repeated three times to yield three independent sets of gamma-ray spectra for each combination of one shadow shield configuration and one type of simulant. As a result, a total of 72 PINS simulant spectra (6 shadow shield configurations $\times 4$ simulants $\times 3$ measurements) and a total of 12 background spectra (two per configuration) were saved to be analyzed at the end of the campaign.

Then, MCNP models of the six mockups have been validated against the experimental data. A typical MCNP model of the experimental setup with one of the six mockups is shown in Figure 2. Each MCNP simulation was run with $1.5 \times 10^{10} \mathrm{D}-\mathrm{D}$ neutrons emitted isotropically, and the pulse height tallies (F8 pulse height tally) were treated with Gaussian Energy Broadening (GEB card) to mimic actual HPGe detector responses. Then, the tally information in the MCNP output file were converted to a MAESTRO ${ }^{\circledR}$ $\mathrm{CHN}$ file. A special version of PINS+ was used to analyze the CHN files in order to bypass the energy recalibration, which is not necessary for the simulated spectra. A collection of the simulated HD simulant and background spectra with the six mockups were analyzed by PINS+ to create spectral analysis results fitted by the Gauss algorithms [3]. The analyzed data provided information of gamma-ray peaks from key chemical elements, and neutron data, i.e. neutron flux to the HPGe detector, were retrieved manually from F4 average cell flux tallies in the MCNP simulation results. The simulated HPGe spectra of the background and the HD simulant are compared to those from experimental campaign in Figure 3.

\section{PERFORMANCE EVALUATION CRITERIA}

Five evaluation criteria were identified to evaluate performance of the shadow shield mockups. In order to calculate each shadow shield design's performance, all five evaluation criteria must be presented as numerical values. Sub-sections below explain how the evaluation criteria were quantified from the MCNP simulation results.

\subsection{Neutron Flux to the HD Simulant $-\Phi_{o b j}$}

A well-designed shadow shield is capable of sending more thermal and fast neutrons toward the HD simulant. More neutron-induced reactions on the key chemical elements (chlorine and sulfur) are expected when the HD simulant is bombarded by more neutrons. Neutron F4 average cell flux was assigned to the HD simulant cell in the MCNP input, and the total neutron flux, $\boldsymbol{\Phi}_{\boldsymbol{o b j}}$, from the tally output in the background spectrum was used to represent the amount of neutrons entering the simulant volume. Therefore, higher $\boldsymbol{\Phi}_{\boldsymbol{o b j}}$ value is desirable to induce more neutron capture and inelastic reactions in the HD simulant. The simulated neutron flux distributions in the HD simulant volume for all six configurations are summarized in Table 1. It could be possible to separate thermal and fast neutron flux distributions as sub-criteria in the future study if thermal neutron capture gamma-rays outweighs inelastic gamma-rays and vice versa. However, all neutrons were considered equally important regardless of their energy in this study.

\subsection{System's Total Weight - $M$}

A well-designed shadow shield must be light-weight to minimize the MIND system's total weight. It is estimated that the total weight of all components, except the shadow shield, would be at least 54lbs. 
Therefore, the system's total weight $\boldsymbol{M}$ was defined to be the sum of the weight of a shadow shield and the remaining 54lbs. It is obvious that lower $\boldsymbol{M}$ value is desirable to make the MIND backpack system more portable. Each design's $\boldsymbol{M}$ value is listed in Table 2.

\subsection{Neutron Flux to the HPGe detector - $\Phi_{\text {det }}$}

A well-designed shadow shield prevents more neutrons from directly hitting the HPGe detector. An assumption was made that neutron damage to the HPGe detector crystal is proportional to the number of neutrons impinging on the detector crystal. Neutron F4 average cell flux was assigned to the HPGe detector cell in the MCNP input, and the total neutron flux, $\boldsymbol{\Phi}_{\text {det }}$, from the tally output in the background spectrum was used to represent the number of neutrons hitting the detector crystal. Lower $\boldsymbol{\Phi}_{\text {det }}$ value is desirable to cause less neutron damage. The simulated neutron flux distributions in the HPGe detector volume for all six configurations are shown in Table 1 . All neutrons were considered equally important regardless of their energy in this study, but neutron energy distribution could be taken into account because high energy neutrons create more knock-out atoms. For example, the mean neutron energy weighted by neutron flux might be another metric to quantify neutron damage in the future study.

\subsection{Neutron-induced Gamma-ray Counts from the HD Simulant - $G$}

Higher gamma-ray counts from chemical elements are favorable as long as spectral quality and dead time remain acceptable. Chlorine and sulfur peaks are key elements to identify HD simulant correctly. The sum of chlorine $1959 \mathrm{keV}$ and sulfur $2230 \mathrm{keV} \boldsymbol{t}^{*}$ values from the PINS+ analysis files was used to represent counting statistics [4]. However, simply higher counts of these two peaks should not be translated into higher performance. In order to take spectral quality into account of performance evaluation, $\left(\boldsymbol{t}^{*} \boldsymbol{C l} 1959 \mathrm{keV}+\boldsymbol{t}^{*}{ }_{\boldsymbol{s}} \mathbf{2 2 3 0 \mathrm { keV }}\right)$ value was multiplied by the identification score, $\boldsymbol{p} \boldsymbol{H D}$, from the PINS+ analysis. As a result, good performance is achieved only when the sum of $\boldsymbol{t}^{*}$ values is large and $\boldsymbol{p H D}$ value is the closest to 1.0 at the same time. Higher $\boldsymbol{G}$ value is required to be a more efficient gamma-ray spectrometer. Each design's calculated $\boldsymbol{G}$ value is listed in Table 2.

\subsection{Hydrogen Factor - $\boldsymbol{H}$}

Large HDPE volume in the shadow shield is ideal to moderate fast neutrons emitted from the neutron generator efficiently, but hydrogen capture gamma-rays from the HDPE itself also interfere with those from the HD simulant. There must be a balance between the neutron moderating power and the selfinduced hydrogen capture gamma-rays. As a metric of such a balance, hydrogen $2223 \mathrm{keV}$ peak's $\boldsymbol{t}^{*}$ value of the HD simulant spectrum was defined as the hydrogen factor $\boldsymbol{H}$. Higher hydrogen $\boldsymbol{t}^{*}$ value implies that $2223 \mathrm{keV}$ gamma-rays from the HD simulant are more dominant than those from the shadow shield as background counts. Clearly, higher $\boldsymbol{H}$ value is desirable for better performance. Each design's $\boldsymbol{H}$ value is listed in Table 2.

\section{PERFORMANCE EVALUATION OF SHADOW SHIELD MOCKUPS}

Each design's five criteria values were prepared from simulation results as discussed above. Then, all criteria values were normalized to their corresponding maximum values as shown in the second half 
(shaded columns) of Table 3. It should be noted that $\boldsymbol{M}$ and $\boldsymbol{\Phi}_{\boldsymbol{d e t}}$ values were inverted to make it simple and intuitive to calculate performance scores, i.e., higher normalized values of $1 / \boldsymbol{M}$ and $1 / \boldsymbol{\Phi}_{\text {det }}$ are required for higher performance.

Two evaluation methods were adopted to represent performance of shadow shield designs numerically, and their approach and evaluation results are discussed below. Equation ((1) was proposed to calculate a design's FoM score by multiplying its five normalized criteria values.

$$
\begin{gathered}
F O M=\frac{\boldsymbol{\Phi}_{\boldsymbol{o b j}} \times\left[\left(t_{C l 1959}^{*}+t_{S 2230}^{*}\right) \times p H D\right] \times t_{H 2223}^{*}}{M \times \boldsymbol{\Phi}_{\text {det }}} \\
=\boldsymbol{\Phi}_{\boldsymbol{o b j}} \times\left(\frac{1}{\boldsymbol{M}}\right) \times\left(\frac{1}{\boldsymbol{\Phi}_{\text {det }}}\right) \times \boldsymbol{G} \times \boldsymbol{H}
\end{gathered}
$$

The FoM equation above explains that higher performance of a shadow shield design could be achieved by more total neutron flux to the simulant (higher $\boldsymbol{\Phi}_{\boldsymbol{o b j}}$ ), lighter shadow shield (higher $1 / \boldsymbol{M}$ ), less total neutron flux to the HPGe detector (higher $1 / \boldsymbol{\Phi}_{\text {det }}$ ), more chlorine and sulfur gamma-ray counts from the HD simulant (higher $\boldsymbol{G}$ ), and more hydrogen $2223 \mathrm{keV}$ net counts in the presence of the HD simulant (higher $\boldsymbol{H}$ ).

Figure 4 shows a hierarchy of performance evaluation of shadow shield designs by AHP method [2]. Each shadow shield design's performance is calculated by

$$
\text { AHP score }=\boldsymbol{\Phi}_{\boldsymbol{o b j}} \times P_{o b j}+\left(\frac{1}{\boldsymbol{M}}\right) \times P_{M}+\left(\frac{1}{\boldsymbol{\Phi}_{\text {det }}}\right) \times P_{d e t}+\boldsymbol{G} \times P_{G}+\boldsymbol{H} \times P_{H}
$$

where $P_{X}$ represents priority value of criterion X. Equation ((2) is interpreted that AHP score is the sum of the five criteria values weighted by their corresponding priority values. Priority values are also required in addition to the criteria values to calculate AHP scores. Therefore, a questionnaire was prepared for four subject matter experts (SME) to rate five criteria's individual importance value on a scale of 1 to 10 as shown in

Table 4. These four survey results were aggregated by the geometric mean into the average values as listed in the last column of

Table 4 . Then, a $5 \times 5$ pair-wise comparison matrix was built from the criteria's average importance values as shown in

Table 5. It has been known that the principal eigenvector of a pair-wise comparison matrix is a vector of priority values [2], and the priority values of the evaluation criteria found in this study are given in the last column of

Table 5.

Equations ((1) and ((2) were applied to the normalized criteria values to calculate FoM and AHP scores, respectively. Each shadow shield mockup's FoM and AHP scores are shown along with its associated normalized criteria values in Table 6. As speculated, the heaviest mockups are the worst performing designs regardless of the shapes of the HDPE block. In order to visualize the results, FoM and AHP scores are plotted as a function of shadow shield's total length and total weight, and areas of bubbles are proportional to scores in Figure 5. The W-M shadow shield mockup performs the best among the six mockups, and the mockups of the truncated wedge outperforms those with the truncated pyramid. However, the results suggested that more shadow shield configurations should be taken into account in an 
expanded performance evaluation, especially shadow shield designs of long total length and light total weight below the dashed lines in Figure 5. Shadow shields of short total length and heavy total weight were excluded in the second round of performance evaluation since they were believed to be poorly performing designs.

\section{EXPANDED STUDY WITH REFINED SHADOW SHIELD DESIGNS}

As suggested in the previous section, more shadow shield designs were included in the expanded study of performance evaluation. 18 new shadow shield designs were modeled and simulated by modifying the models of the six mockups: lengths of the HDPE and the tungsten blocks were varied to make total lengths 4, 5 or 6"-long while keeping the other dimensions the same. All the other components in the MCNP models were simply re-positioned accordingly to reflect changes made in the shadow shields. A total of 24 shadow shield designs, including the six mockups, were evaluated in the expanded study. The same procedure as discussed in the previous section was followed with the 24 shadow shield designs. Table 7 shows specifications, normalized criteria values and final scores of the 24 configurations. Figure 6 shows two bubble charts of the FoM and AHP scores with their associated total weights and total lengths. W331545 and W331050 scored as the best performing designs by FoM and AHP methods, respectively. W331050 was considered the best configuration due to its lighter weight than W331545 by 3lbs.

In general, HDPE blocks of the truncated wedge outperform those of the truncated pyramid. Also, performance of a shadow shield seems most sensitive to the total length. Most evaluation criteria values can be approximated as functions of the total length except for $1 / \boldsymbol{M}$, which is governed mainly by the volume of a tungsten block. Figure 7 shows that $1 / \boldsymbol{\Phi}_{\boldsymbol{d e t}}$ increases rapidly and $\boldsymbol{\Phi}_{\boldsymbol{o b j}}, \boldsymbol{G}$, and $\boldsymbol{H}$ decrease slowly as the total length increases. For the fixed total length of 6", the normalized criteria values are related to the HDPE-to-tungsten length ratio as shown in Figure 8. 1/M value increases as the HDPE-totungsten ratio increases while $1 / \boldsymbol{\Phi}_{\boldsymbol{d e t}}$ and $\boldsymbol{H}$ values decrease as the HDPE-to-tungsten ratio increases. $\boldsymbol{\Phi}_{\boldsymbol{o b j}}$ and $\boldsymbol{G}$ are not as very sensitive to the ratio as the other criteria, but 5:1 ratio seems the most balanced configuration.

\section{SUMMARY}

A shadow shield of low-mass and low-volume was designed for the MIND backpack system by MCNP modeling and simulation. Both FoM and AHP methods were applied to the MCNP simulation results to determine the best performing design. Five evaluation criteria were identified to evaluate 24 possible shadow shield configurations. The final shadow shield for the MIND backpack system was determined to be a combination of a 5"-long truncated wedge HDPE block $(3$ " $\times 3$ " wide side and 1.5 " $\times 3$ " narrower side) and a 1"-long tungsten block ( 3 " $\times 3$ " square) as illustrated in Figure 9. This shadow shield alone weighs about $7.4 \mathrm{lbs}$ (6.3lbs tungsten and $1.1 \mathrm{lbs}$ HDPE), and the total weight of the MIND backpack system is estimated to be about 62lbs excluding a backpack. 


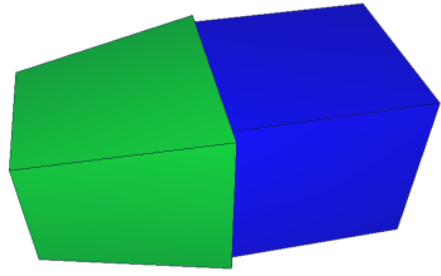

Configuration P-W (pyramid HDPE + medium W)

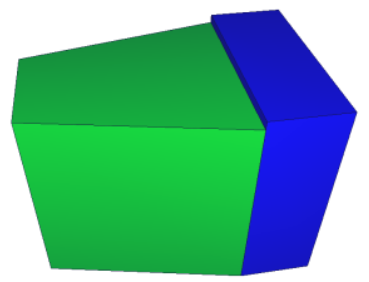

Configuration W-S (wedge HDPE + small W)

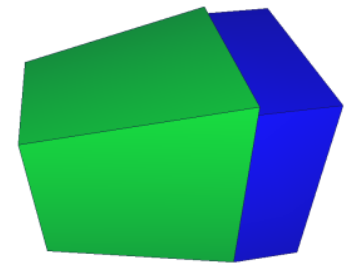

Configuration P-S

(pyramid HDPE + small W)

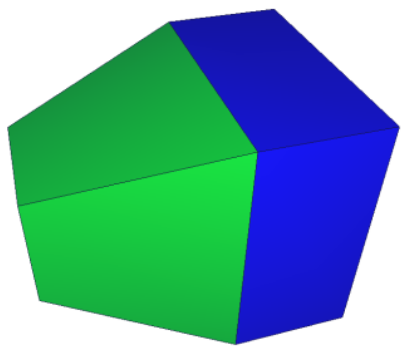

Configuration P-L (pyramid HDPE + large W)

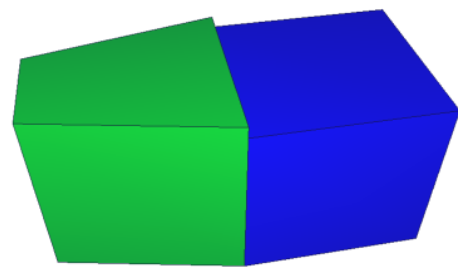

Configuration W-M (wedge HDPE + medium W)

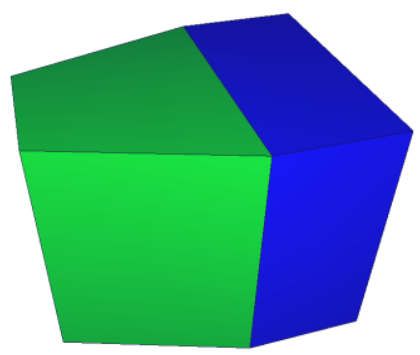

Configuration W-L (wedge HDPE + large W)

Figure 1. MCNP models of six unique shadow shield configurations. Actual dimensions of the HDPE (green) and tungsten (blue) blocks were used to reproduce these shadow shield in MCNP input decks.
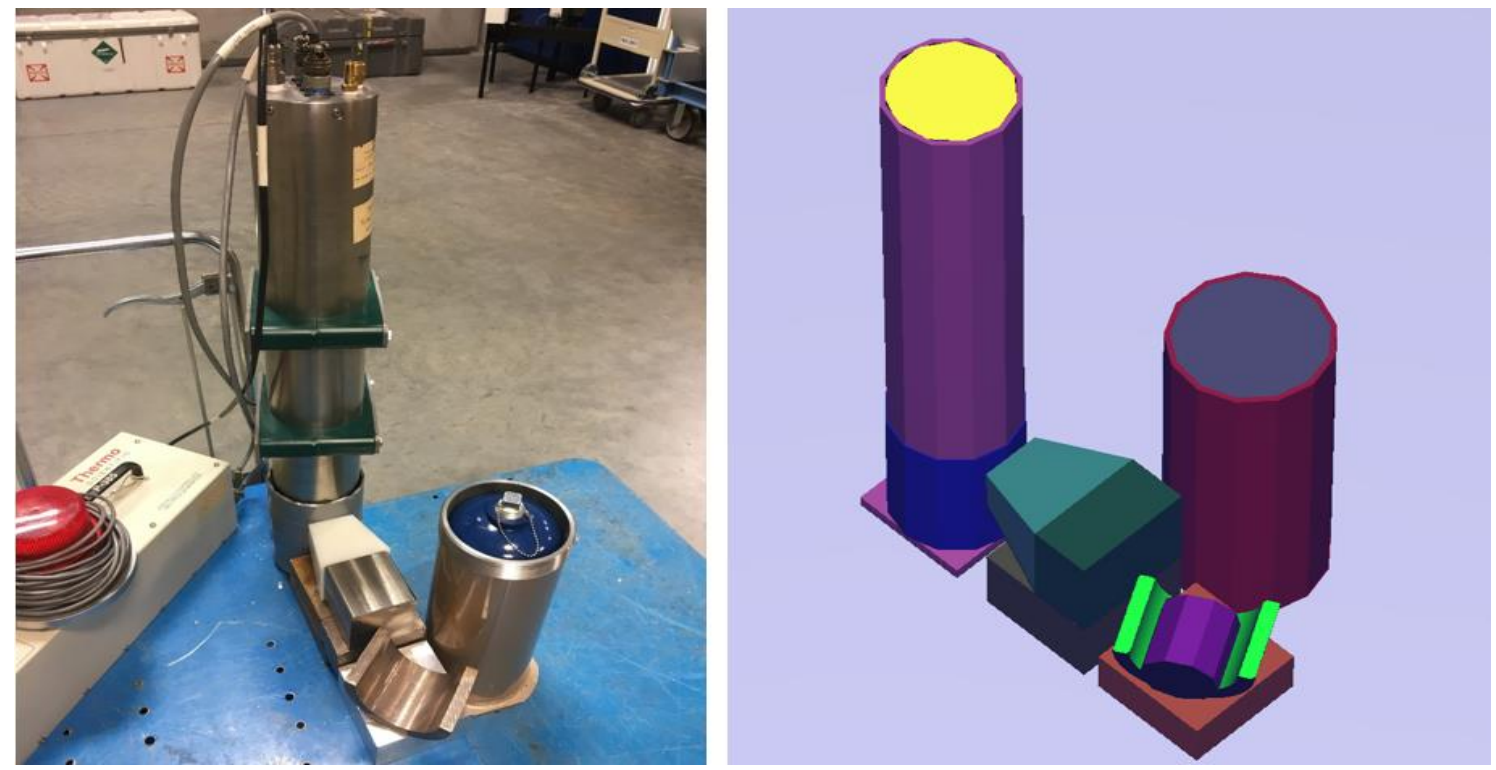

Figure 2. MCNP model of laboratory setup with the shadow shield configuration \#5 in place. MCNP models were built to describe as close to the real setups as possible. As discussed above, the generator 
control module and the blue cart were not modeled under the assumption that those have negligible impact on the simulation results.

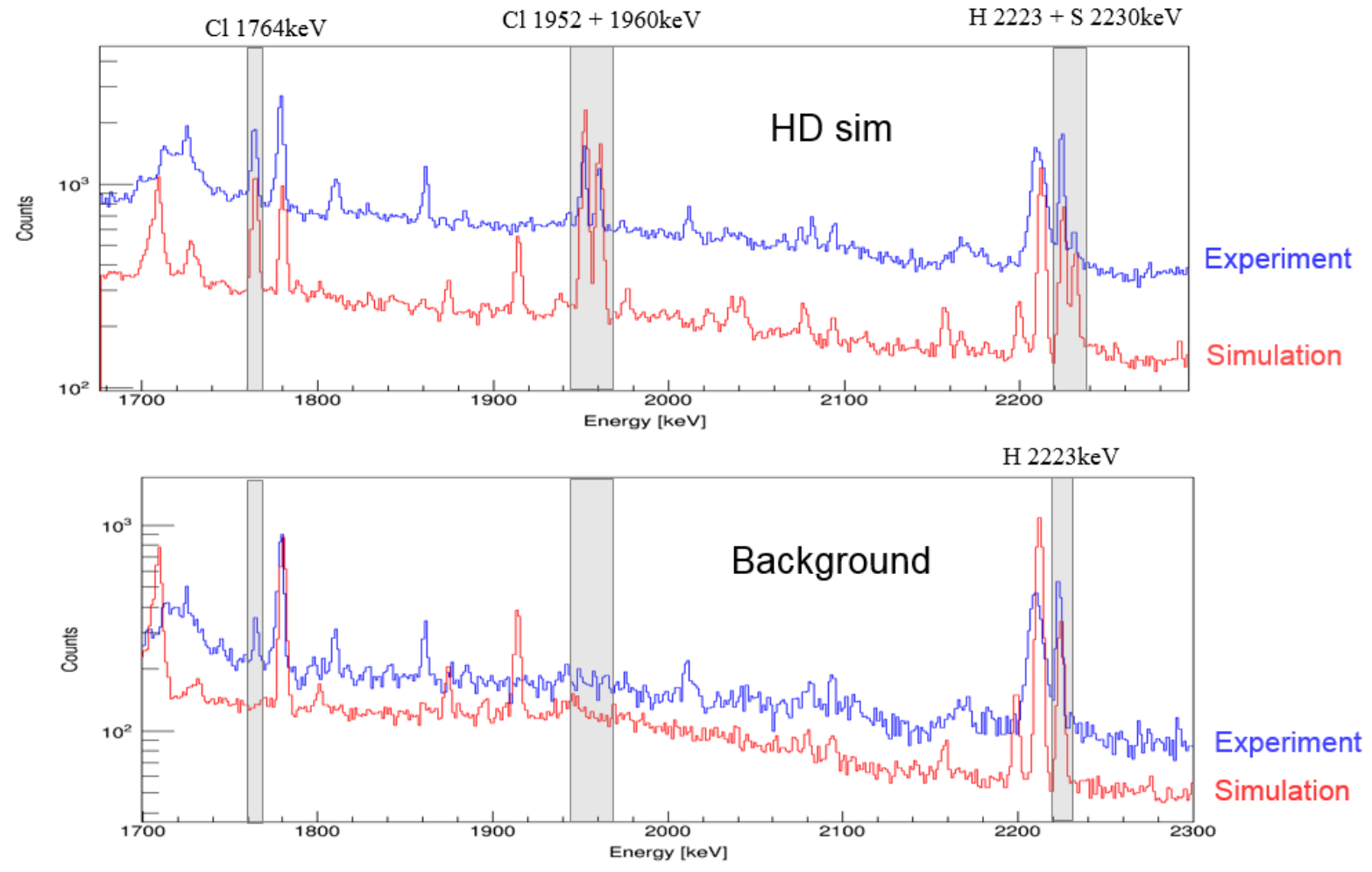

Figure 3. Comparison between simulated (red) and experimental (blue) gamma-ray spectra for the background and the HD simulant, respectively. Chlorine and sulfur peaks are observed only in the presence of the HD simulant while hydrogen peaks are visible in both cases. Hydrogen peak in the background spectra are from the HDPE block in the shadow shield.

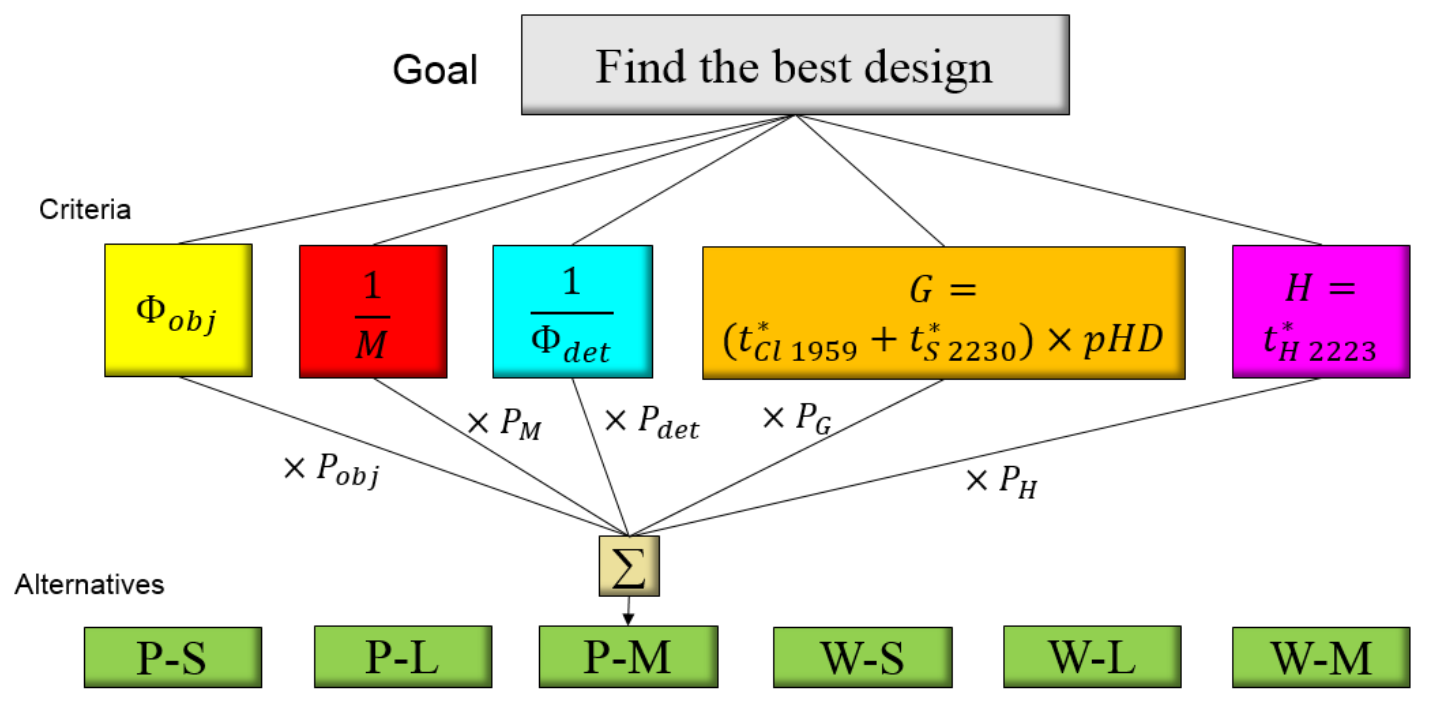

Figure 4. A simple hierarchy to select the best shadow shield design in AHP method. A shadow shield design's score is the sum of the five criteria values weighted by their corresponding priorities. 

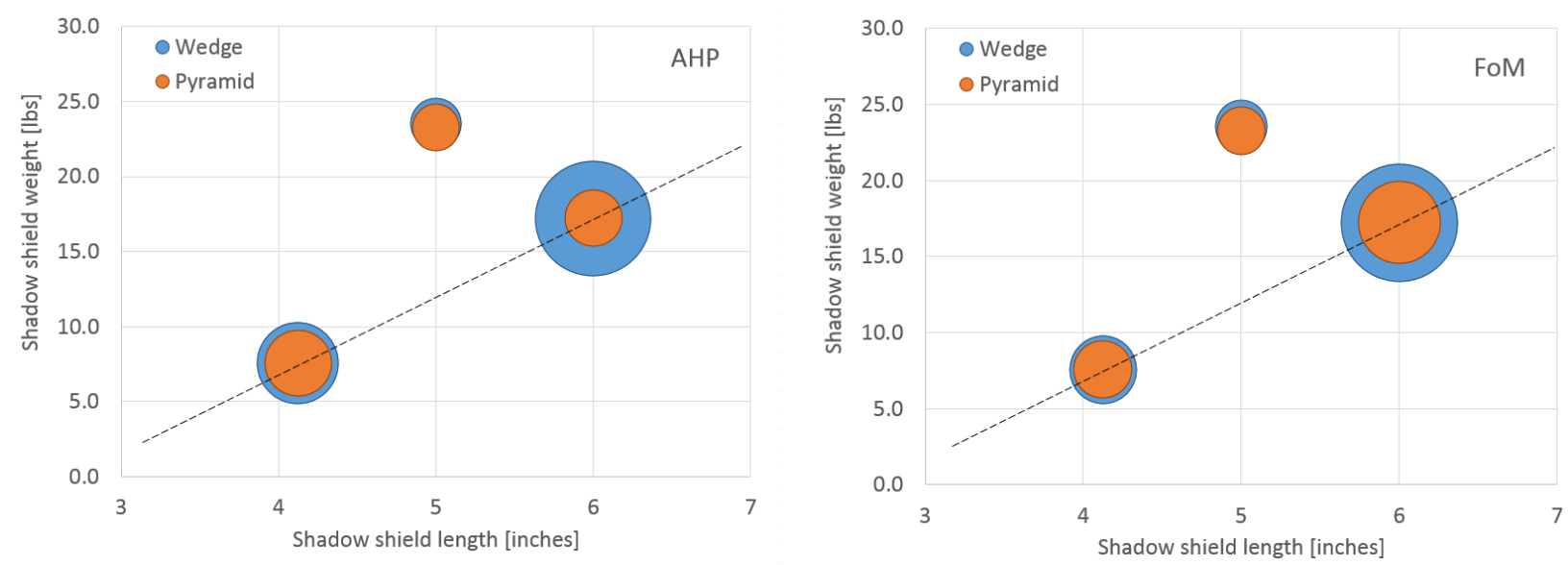

Figure 5. The calculated scores of the six mockups by AHP (left) and FoM (right) methods. Each bubble is plotted with its associated shadow shield's weight and total length, and the area of the bubble is proportional to its score. For similar configurations, HDPE blocks of the truncated wedge perform better than the truncated pyramid. More candidate designs that lie below the dashed lines were included in the expanded study.
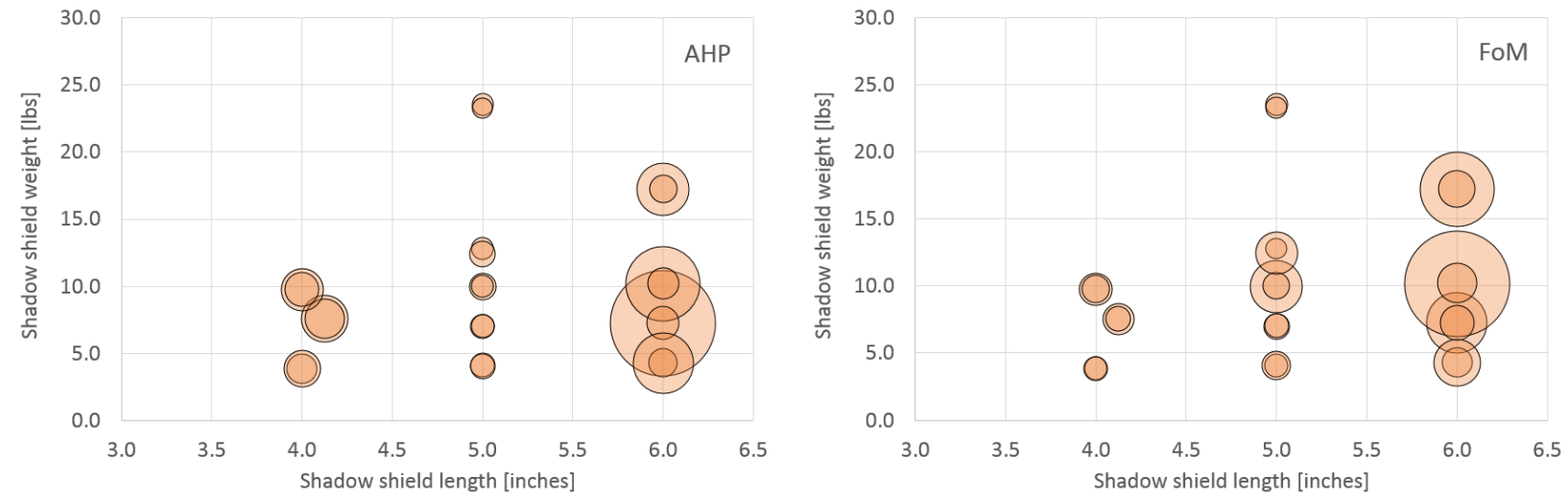

Figure 6. The calculated scores of the 24 shadow shield configurations by AHP (left) and FoM (right) methods. Shadow shield designs of 6" total length were found to be ideal configurations in general. The shadow shield composed of 1"-long tungsten and 5"-long HDPE blocks was selected as the best configuration by AHP method, and 1.5"-long tungsten and 4.5"-long HDPE blocks was selected as the best configuration by FoM method. 


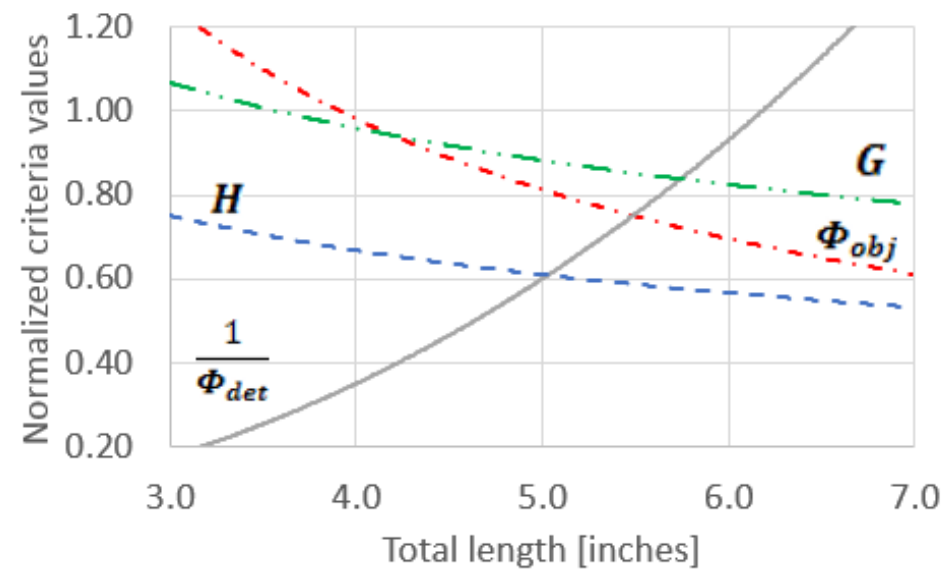

Figure 7. Behaviors of the four criteria values are well described as functions of shadow shield total length, respectively. However, the $1 / \boldsymbol{M}$ criteria is directly related to tungsten block's volume, not total length.
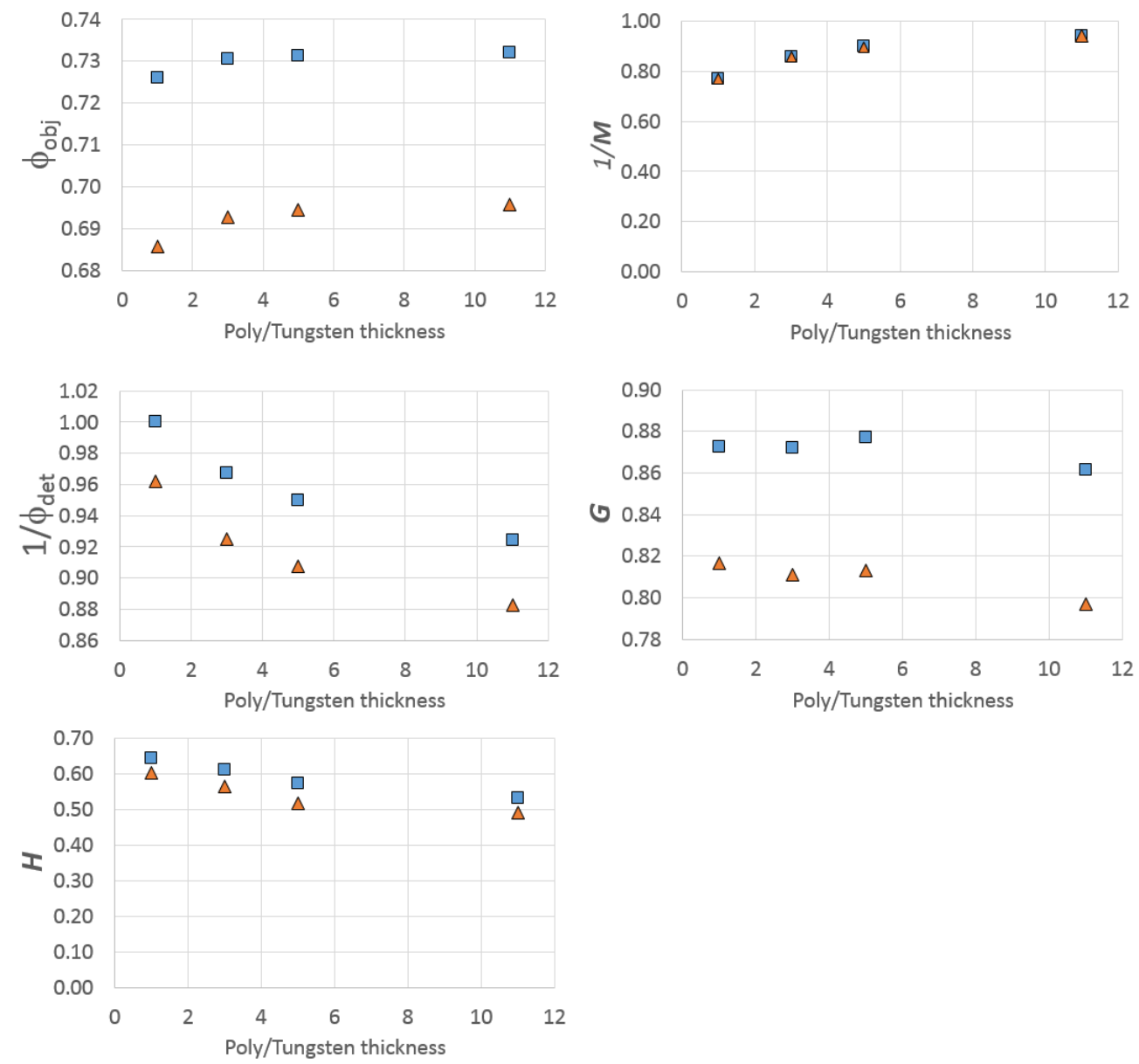

Figure 8. Behaviors of the five criteria values (blue squares are for the truncated wedge and orange triangles are for the truncated pyramid) are shown as function of the ratio of HDPE-to-tungsten length for the total length of 6". Four different ratios correspond to the configurations of $3 " / 3 ", 4.5 " / 1.5 ", 5 " / 1 "$, and $5.5 \% / 0.5 "$ in HDPE-to-tungsten length, respectively. 


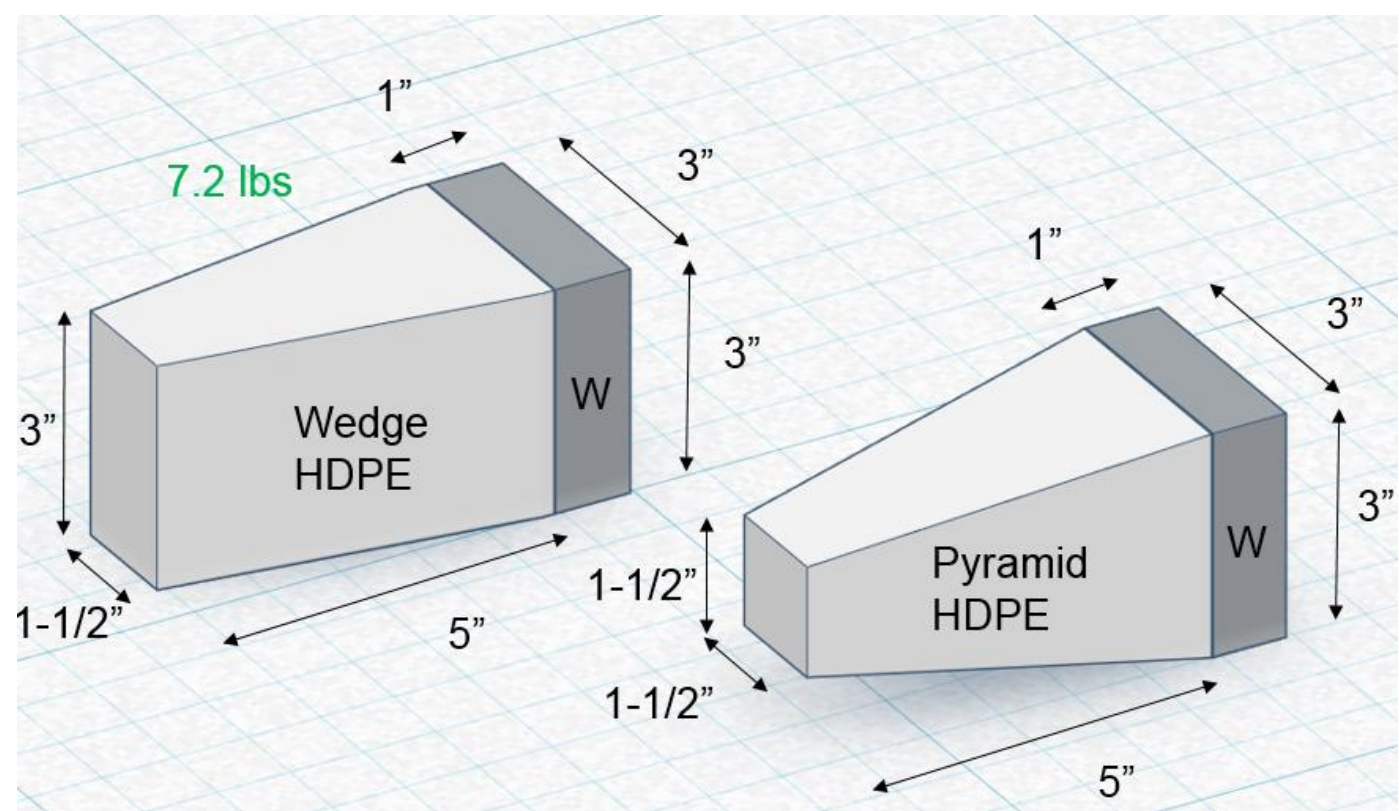

Figure 9. The final shadow shield design (left) from the simulation-based study. The shadow shield with the truncated pyramid (right) is also fabricated to be another reference design to validate MCNP models of the MIND system in the future. 
Table 1. Simulated neutron energy distributions inside the HD simulant volume $\left(\boldsymbol{\Phi}_{\boldsymbol{o b j}}\right)$ and the HPGe detector volume $\left(\boldsymbol{\Phi}_{\text {det }}\right)$ from the MCNP simulation results. The total neutron flux distributions in the last row were used to quantify $\boldsymbol{\Phi}_{\boldsymbol{o b j}}$ and $1 / \boldsymbol{\Phi}_{\boldsymbol{d e t}}$.

\begin{tabular}{|c|c|c|c|c|c|c|c|c|c|c|c|c|}
\hline \multirow{2}{*}{$\begin{array}{c}\mathrm{E} \\
{[\mathrm{MeV}]}\end{array}$} & \multicolumn{6}{|c|}{$\boldsymbol{\Phi}_{\boldsymbol{o b j}}\left[\# / \mathrm{cm}^{2} / \mathrm{nps}\right]$} & \multicolumn{6}{|c|}{$\boldsymbol{\Phi}_{\boldsymbol{d e t}}\left[\# / \mathrm{cm}^{2} / \mathrm{nps}\right]$} \\
\hline & $\mathrm{W}-\mathrm{S}$ & W-L & W-M & P-S & P-L & P-M & $\mathrm{W}-\mathrm{S}$ & W-L & W-M & P-S & P-L & P-M \\
\hline $0.00 \mathrm{E}+0$ & $0.00 \mathrm{E}+0$ & $0.00 \mathrm{E}+0$ & $0.00 \mathrm{E}+0$ & $0.00 \mathrm{E}+0$ & $0.00 \mathrm{E}+0$ & $0.00 \mathrm{E}+0$ & $0.00 \mathrm{E}+0$ & $0.00 \mathrm{E}+0$ & $0.00 \mathrm{E}+0$ & $0.00 \mathrm{E}+0$ & $0.00 \mathrm{E}+0$ & $0.00 \mathrm{E}+0$ \\
\hline $1.00 \mathrm{E}-6$ & $1.79 \mathrm{E}-6$ & $2.02 \mathrm{E}-6$ & $1.31 \mathrm{E}-6$ & $1.86 \mathrm{E}-6$ & $1.57 \mathrm{E}-6$ & $1.35 \mathrm{E}-6$ & $6.85 \mathrm{E}-7$ & $6.35 \mathrm{E}-7$ & $5.36 \mathrm{E}-7$ & $7.00 \mathrm{E}-7$ & $6.09 \mathrm{E}-7$ & $5.47 \mathrm{E}-7$ \\
\hline $1.00 \mathrm{E}-5$ & $5.09 \mathrm{E}-7$ & $5.23 \mathrm{E}-7$ & $3.66 \mathrm{E}-7$ & $5.25 \mathrm{E}-7$ & $4.28 \mathrm{E}-7$ & $3.75 \mathrm{E}-7$ & $2.82 \mathrm{E}-7$ & $2.42 \mathrm{E}-7$ & $1.63 \mathrm{E}-7$ & $2.91 \mathrm{E}-7$ & $2.24 \mathrm{E}-7$ & $1.68 \mathrm{E}-7$ \\
\hline $1.00 \mathrm{E}-4$ & $6.29 \mathrm{E}-7$ & $6.35 \mathrm{E}-7$ & $4.49 \mathrm{E}-7$ & $6.47 \mathrm{E}-7$ & $5.25 \mathrm{E}-7$ & $4.59 \mathrm{E}-7$ & $3.50 \mathrm{E}-7$ & $3.34 \mathrm{E}-7$ & $2.07 \mathrm{E}-7$ & $3.58 \mathrm{E}-7$ & $3.09 \mathrm{E}-7$ & $2.14 \mathrm{E}-7$ \\
\hline $1.00 \mathrm{E}-3$ & $8.00 \mathrm{E}-7$ & $8.11 \mathrm{E}-7$ & $5.75 \mathrm{E}-7$ & $8.22 \mathrm{E}-7$ & $6.79 \mathrm{E}-7$ & $5.88 \mathrm{E}-7$ & $4.69 \mathrm{E}-7$ & $4.47 \mathrm{E}-7$ & $2.43 \mathrm{E}-7$ & $4.86 \mathrm{E}-7$ & $4.11 \mathrm{E}-7$ & $2.52 \mathrm{E}-7$ \\
\hline $1.00 \mathrm{E}-2$ & $1.06 \mathrm{E}-6$ & $1.06 \mathrm{E}-6$ & $7.55 \mathrm{E}-7$ & $1.08 \mathrm{E}-6$ & $8.92 \mathrm{E}-7$ & 7.71E-7 & $6.41 \mathrm{E}-7$ & $6.23 \mathrm{E}-7$ & $3.22 \mathrm{E}-7$ & $6.62 \mathrm{E}-7$ & $5.81 \mathrm{E}-7$ & $3.35 \mathrm{E}-7$ \\
\hline $1.00 \mathrm{E}-1$ & $1.89 \mathrm{E}-6$ & $1.91 \mathrm{E}-6$ & $1.39 \mathrm{E}-6$ & $1.92 \mathrm{E}-6$ & $1.66 \mathrm{E}-6$ & $1.41 \mathrm{E}-6$ & $1.35 \mathrm{E}-6$ & $1.43 \mathrm{E}-6$ & $6.75 \mathrm{E}-7$ & $1.40 \mathrm{E}-6$ & $1.41 \mathrm{E}-6$ & $7.04 \mathrm{E}-7$ \\
\hline $1.00 \mathrm{E}+0$ & $1.04 \mathrm{E}-5$ & $9.84 \mathrm{E}-6$ & $7.52 \mathrm{E}-6$ & $1.05 \mathrm{E}-5$ & $9.28 \mathrm{E}-6$ & $7.56 \mathrm{E}-6$ & $1.07 \mathrm{E}-5$ & $1.02 \mathrm{E}-5$ & $4.86 \mathrm{E}-6$ & $1.13 \mathrm{E}-5$ & $1.11 \mathrm{E}-5$ & $5.11 \mathrm{E}-6$ \\
\hline $1.44 \mathrm{E}+0$ & $4.90 \mathrm{E}-6$ & $4.50 \mathrm{E}-6$ & $3.70 \mathrm{E}-6$ & $5.03 \mathrm{E}-6$ & $4.26 \mathrm{E}-6$ & $3.60 \mathrm{E}-6$ & $3.87 \mathrm{E}-6$ & $2.89 \mathrm{E}-6$ & $1.55 \mathrm{E}-6$ & $4.11 \mathrm{E}-6$ & $3.21 \mathrm{E}-6$ & $1.62 \mathrm{E}-6$ \\
\hline $1.89 \mathrm{E}+0$ & $5.96 \mathrm{E}-6$ & $5.26 \mathrm{E}-6$ & $4.59 \mathrm{E}-6$ & $6.35 \mathrm{E}-6$ & $5.34 \mathrm{E}-6$ & $4.56 \mathrm{E}-6$ & $4.46 \mathrm{E}-6$ & $2.92 \mathrm{E}-6$ & $1.53 \mathrm{E}-6$ & $4.86 \mathrm{E}-6$ & $3.60 \mathrm{E}-6$ & $1.62 \mathrm{E}-6$ \\
\hline $2.33 \mathrm{E}+0$ & $5.87 \mathrm{E}-6$ & $5.94 \mathrm{E}-6$ & $4.93 \mathrm{E}-6$ & $6.12 \mathrm{E}-6$ & $5.64 \mathrm{E}-6$ & $5.09 \mathrm{E}-6$ & $4.16 \mathrm{E}-6$ & $2.91 \mathrm{E}-6$ & $1.93 \mathrm{E}-6$ & $4.32 \mathrm{E}-6$ & $3.10 \mathrm{E}-6$ & $1.99 \mathrm{E}-6$ \\
\hline $2.78 \mathrm{E}+0$ & $1.53 \mathrm{E}-4$ & $1.23 \mathrm{E}-4$ & $1.10 \mathrm{E}-4$ & $1.52 \mathrm{E}-4$ & $1.26 \mathrm{E}-4$ & $1.03 \mathrm{E}-4$ & $1.13 \mathrm{E}-5$ & $5.54 \mathrm{E}-6$ & $2.72 \mathrm{E}-6$ & $1.20 \mathrm{E}-5$ & $7.26 \mathrm{E}-6$ & $2.76 \mathrm{E}-6$ \\
\hline $3.22 \mathrm{E}+0$ & $0.00 \mathrm{E}+0$ & $0.00 \mathrm{E}+0$ & $0.00 \mathrm{E}+0$ & $0.00 \mathrm{E}+0$ & $0.00 \mathrm{E}+0$ & $0.00 \mathrm{E}+0$ & $0.00 \mathrm{E}+0$ & $0.00 \mathrm{E}+0$ & $0.00 \mathrm{E}+0$ & $0.00 \mathrm{E}+0$ & $0.00 \mathrm{E}+0$ & $0.00 \mathrm{E}+0$ \\
\hline $3.67 \mathrm{E}+0$ & $0.00 \mathrm{E}+0$ & $0.00 \mathrm{E}+0$ & $0.00 \mathrm{E}+0$ & $0.00 \mathrm{E}+0$ & $0.00 \mathrm{E}+0$ & $0.00 \mathrm{E}+0$ & $0.00 \mathrm{E}+0$ & $0.00 \mathrm{E}+0$ & $0.00 \mathrm{E}+0$ & $0.00 \mathrm{E}+0$ & $0.00 \mathrm{E}+0$ & $0.00 \mathrm{E}+0$ \\
\hline $4.11 \mathrm{E}+0$ & $0.00 \mathrm{E}+0$ & $0.00 \mathrm{E}+0$ & $0.00 \mathrm{E}+0$ & $0.00 \mathrm{E}+0$ & $0.00 \mathrm{E}+0$ & $0.00 \mathrm{E}+0$ & $0.00 \mathrm{E}+0$ & $0.00 \mathrm{E}+0$ & $0.00 \mathrm{E}+0$ & $0.00 \mathrm{E}+0$ & $0.00 \mathrm{E}+0$ & $0.00 \mathrm{E}+0$ \\
\hline $4.56 \mathrm{E}+0$ & $0.00 \mathrm{E}+0$ & $0.00 \mathrm{E}+0$ & $0.00 \mathrm{E}+0$ & $0.00 \mathrm{E}+0$ & $0.00 \mathrm{E}+0$ & $0.00 \mathrm{E}+0$ & $0.00 \mathrm{E}+0$ & $0.00 \mathrm{E}+0$ & $0.00 \mathrm{E}+0$ & $0.00 \mathrm{E}+0$ & $0.00 \mathrm{E}+0$ & $0.00 \mathrm{E}+0$ \\
\hline $5.00 \mathrm{E}+0$ & $0.00 \mathrm{E}+0$ & $0.00 \mathrm{E}+0$ & $0.00 \mathrm{E}+0$ & $0.00 \mathrm{E}+0$ & $0.00 \mathrm{E}+0$ & $0.00 \mathrm{E}+0$ & $0.00 \mathrm{E}+0$ & $0.00 \mathrm{E}+0$ & $0.00 \mathrm{E}+0$ & $0.00 \mathrm{E}+0$ & $0.00 \mathrm{E}+0$ & $0.00 \mathrm{E}+0$ \\
\hline Total & $1.87 E-4$ & $1.56 \mathrm{E}-4$ & $1.36 \mathrm{E}-4$ & $1.87 \mathrm{E}-4$ & $1.57 \mathrm{E}-4$ & $1.28 \mathrm{E}-4$ & 3.82E-5 & $2.82 \mathrm{E}-5$ & $1.47 \mathrm{E}-5$ & 4.05E-5 & 3.18E-5 & $1.53 \mathrm{E}-5$ \\
\hline
\end{tabular}

Table 2. $\boldsymbol{M}, \boldsymbol{G}$ and $\boldsymbol{H}$ criteria values for the six mockups.

\begin{tabular}{|c|c|c|c|c|c|c|c|}
\hline Config. & $\begin{array}{l}\text { Shadow } \\
\text { shield } \\
\text { weight [lbs] }\end{array}$ & $\begin{array}{c}\boldsymbol{M} \\
{[\mathrm{lbs}]}\end{array}$ & $t^{*}{ }_{C l} 1959$ & $t_{S 2230}^{*}$ & $p H D$ & $\begin{array}{c}G= \\
\left(\boldsymbol{t}^{*}{ }_{C l 1959}+\boldsymbol{t}^{*}{ }_{S 2230}\right) \\
\times p H D\end{array}$ & $\begin{array}{c}H= \\
t^{*}{ }_{H 223}\end{array}$ \\
\hline W-S & 7.56 & 61.56 & 50.41 & 19.47 & 1.00 & 69.88 & 16.02 \\
\hline W-L & 23.55 & 77.55 & 47.27 & 15.51 & 1.00 & 62.78 & 15.20 \\
\hline W-M & 17.21 & 71.21 & 43.94 & 17.76 & 1.00 & 61.70 & 15.32 \\
\hline P-S & 7.58 & 61.58 & 49.92 & 20.07 & 1.00 & 69.99 & 15.87 \\
\hline P-L & 23.27 & 77.27 & 45.69 & 17.62 & 1.00 & 63.31 & 15.57 \\
\hline P-M & 17.23 & 71.23 & 41.66 & 16.06 & 1.00 & 57.72 & 14.39 \\
\hline
\end{tabular}


Table 3. $\boldsymbol{\Phi}_{\boldsymbol{o b j}}, 1 / \boldsymbol{M}, 1 / \boldsymbol{\Phi}_{\boldsymbol{d e t}}, \boldsymbol{G}$ and $\boldsymbol{H}$ criteria values for the six mockups. The column normalized criteria values were used for Equation ((1) and ((2).

\begin{tabular}{|c|c|c|c|c|c|c|c|c|c|c|}
\hline \multirow[b]{2}{*}{ Config. } & \multirow[b]{2}{*}{$\begin{array}{c}\boldsymbol{\Phi}_{\boldsymbol{o b j}} \\
{\left[\# / \mathrm{cm}^{2} / \mathrm{nps}\right]}\end{array}$} & \multirow[b]{2}{*}{$\begin{array}{c}\boldsymbol{M} \\
{[\mathrm{lbs}]}\end{array}$} & \multirow[b]{2}{*}{$\begin{array}{c}\boldsymbol{\Phi}_{\text {det }} \\
{\left[\# / \mathrm{cm}^{2} / \mathrm{nps}\right]}\end{array}$} & \multirow[b]{2}{*}{$G$} & \multirow[b]{2}{*}{$\boldsymbol{H}$} & \multicolumn{5}{|c|}{ Column normalized } \\
\hline & & & & & & $\Phi_{o b j}$ & $\frac{1}{M}$ & $\frac{1}{\Phi_{d e t}}$ & $G$ & $\boldsymbol{H}$ \\
\hline $\mathrm{W}-\mathrm{S}$ & $1.87 \mathrm{E}-4$ & 61.56 & $3.82 \mathrm{E}-5$ & 69.88 & 16.02 & 1.00 & 1.00 & 0.39 & 1.00 & 1.00 \\
\hline W-L & $1.56 \mathrm{E}-4$ & 77.55 & $2.82 \mathrm{E}-5$ & 62.78 & 15.20 & 0.83 & 0.79 & 0.52 & 0.90 & 0.95 \\
\hline W-M & $1.36 \mathrm{E}-4$ & 71.21 & $1.47 \mathrm{E}-5$ & 61.70 & 15.32 & 0.73 & 0.86 & 1.00 & 0.88 & 0.96 \\
\hline $\mathrm{P}-\mathrm{S}$ & $1.87 \mathrm{E}-4$ & 61.58 & $4.05 \mathrm{E}-5$ & 69.99 & 15.87 & 1.00 & 1.00 & 0.36 & 1.00 & 0.99 \\
\hline P-L & $1.57 \mathrm{E}-4$ & 77.27 & $3.18 \mathrm{E}-5$ & 63.31 & 15.57 & 0.84 & 0.80 & 0.46 & 0.90 & 0.97 \\
\hline P-M & $1.28 \mathrm{E}-4$ & 71.23 & $1.53 \mathrm{E}-5$ & 57.72 & 14.39 & 0.69 & 0.86 & 0.96 & 0.82 & 0.90 \\
\hline
\end{tabular}

Table 4. Survey results from four SMEs. Each criterion was aggregated by taking the geometric mean of four ratings.

\begin{tabular}{|c|c|c|c|c|c|}
\hline Criteria & SME \#1 & SME \#2 & SME \#3 & SME \#4 & Geometric mean \\
\hline $\boldsymbol{\Phi}_{\text {obj }}$ & 8 & 7 & 6 & 8 & 7.2 \\
\hline$\frac{1}{\boldsymbol{M}}$ & 5 & 6 & 8 & 3 & 5.2 \\
\hline$\frac{1}{\boldsymbol{\Phi}_{\text {det }}}$ & 7 & 7 & 7 & 5 & 6.4 \\
\hline $\boldsymbol{G}$ & 8 & 5 & 6 & 9 & 6.8 \\
\hline $\boldsymbol{H}$ & 7 & 1 & 1 & 6 & 2.6 \\
\hline
\end{tabular}

Table 5. The pairwise comparison matrix from the SME survey results. The priority values in the last column were obtained from the matrix's principal eigenvector.

\begin{tabular}{|c|c|c|c|c|c|c|c|}
\hline $\begin{array}{c}\text { Criteri } \\
\text { a }\end{array}$ & $\boldsymbol{\Phi}_{\text {obj }}$ & $\frac{1}{\boldsymbol{M}}$ & $\frac{1}{\boldsymbol{\Phi}_{\text {det }}}$ & $\boldsymbol{G}$ & $\boldsymbol{H}$ & \multicolumn{2}{|c|}{$\begin{array}{c}\text { Priority } \\
\boldsymbol{P}\end{array}$} \\
\hline $\boldsymbol{\Phi}_{\boldsymbol{o b j}}$ & 1.000 & 1.390 & 1.119 & 1.056 & 2.828 & $\boldsymbol{P}_{\boldsymbol{o b j}}$ & 0.256 \\
\hline$\frac{1}{\boldsymbol{M}}$ & 0.719 & 1.000 & 0.805 & 0.760 & 2.035 & $\boldsymbol{P}_{\boldsymbol{M}}$ & 0.184 \\
\hline$\frac{1}{\boldsymbol{\Phi}_{\text {det }}}$ & 0.893 & 1.25 & 1.000 & 0.944 & 2.528 & $\boldsymbol{P}_{\text {det }}$ & 0.228 \\
\hline $\boldsymbol{G}$ & 0.943 & 1.316 & 1.064 & 1.000 & 2.678 & $\boldsymbol{P}_{\boldsymbol{G}}$ & 0.242 \\
\hline $\boldsymbol{H}$ & 0.353 & 0.493 & 0.395 & 0.373 & 1.000 & $\boldsymbol{P}_{\boldsymbol{H}}$ & 0.090 \\
\hline
\end{tabular}


Table 6. FoM and AHP scores for the six mockups.

\begin{tabular}{cccccccc}
\hline Config. & $\boldsymbol{\Phi}_{\boldsymbol{o b j}}$ & $\frac{\mathbf{1}}{\boldsymbol{M}}$ & $\frac{\mathbf{1}}{\boldsymbol{\Phi}_{\text {det }}}$ & $\boldsymbol{G}$ & $\boldsymbol{H}$ & $\begin{array}{c}\text { FoM } \\
\text { score }\end{array}$ & $\begin{array}{c}\text { AHP } \\
\text { score }\end{array}$ \\
\hline W-S & 1.00 & 1.00 & 0.39 & 1.00 & 1.00 & 0.385 & 0.859 \\
W-L & 0.83 & 0.79 & 0.52 & 0.90 & 0.95 & 0.294 & 0.775 \\
W-M & 0.73 & 0.86 & 1.00 & 0.88 & 0.96 & 0.529 & 0.869 \\
P-S & 1.00 & 1.00 & 0.36 & 1.00 & 0.99 & 0.361 & 0.854 \\
P-L & 0.84 & 0.80 & 0.46 & 0.90 & 0.97 & 0.272 & 0.768 \\
P-M & 0.69 & 0.86 & 0.96 & 0.82 & 0.90 & 0.423 & 0.831 \\
\hline
\end{tabular}

Table 7. FoM and AHP scores for the all 24 configurations evaluated in the expanded study.

\begin{tabular}{|c|c|c|c|c|c|c|c|c|c|c|c|}
\hline \multirow[b]{2}{*}{$\begin{array}{l}\text { Config. } \\
\text { identifier }\end{array}$} & \multirow{2}{*}{$\begin{array}{c}\text { Shadow } \\
\text { shield } \\
\text { total } \\
\text { weight } \\
\text { [lbs] }\end{array}$} & \multirow{2}{*}{$\begin{array}{c}\text { Shadow } \\
\text { shield } \\
\text { total } \\
\text { length } \\
\text { [inches] }\end{array}$} & \multirow{2}{*}{$\begin{array}{l}\text { Tungsten } \\
\text { Length } \\
\text { [inches] }\end{array}$} & \multirow{2}{*}{$\begin{array}{c}\text { Poly } \\
\text { Length } \\
\text { [inches] }\end{array}$} & \multicolumn{5}{|c|}{ Normalized criteria } & \multirow[b]{2}{*}{$\begin{array}{l}\text { FoM } \\
\text { score }\end{array}$} & \multirow[b]{2}{*}{$\begin{array}{l}\text { AHP } \\
\text { score }\end{array}$} \\
\hline & & & & & $\Phi_{o b j}$ & $\frac{1}{M}$ & $\frac{1}{\Phi_{\text {det }}}$ & $G$ & $\boldsymbol{H}$ & & \\
\hline W-S & 7.6 & 4.1 & 1.1 & 3.0 & 1.00 & 0.93 & 0.39 & 0.99 & 0.67 & 0.240 & 0.816 \\
\hline W-L & 23.5 & 5.0 & 2.0 & 3.0 & 0.83 & 0.71 & 0.52 & 0.89 & 0.64 & 0.183 & 0.741 \\
\hline W-M & 17.2 & 6.0 & 3.0 & 3.0 & 0.73 & 0.79 & 1.00 & 0.87 & 0.64 & 0.331 & 0.832 \\
\hline $\mathrm{P}-\mathrm{S}$ & 7.6 & 4.1 & 1.1 & 3.0 & 1.00 & 0.93 & 0.36 & 0.99 & 0.67 & 0.225 & 0.811 \\
\hline P-L & 23.3 & 5.0 & 2.0 & 3.0 & 0.84 & 0.72 & 0.46 & 0.90 & 0.65 & 0.170 & 0.733 \\
\hline P-M & 17.2 & 6.0 & 3.0 & 3.0 & 0.69 & 0.78 & 0.96 & 0.82 & 0.60 & 0.264 & 0.796 \\
\hline W331040 & 7.0 & 5.0 & 1.0 & 4.0 & 0.73 & 0.94 & 0.71 & 0.85 & 0.54 & 0.226 & 0.778 \\
\hline W331050 & 7.2 & 6.0 & 1.0 & 5.0 & 0.73 & 0.93 & 0.95 & 0.88 & 0.57 & 0.329 & 0.841 \\
\hline W331525 & 9.7 & 4.0 & 1.5 & 2.5 & 1.00 & 0.89 & 0.37 & 1.00 & 0.72 & 0.243 & 0.814 \\
\hline W331535 & 10.0 & 5.0 & 1.5 & 3.5 & 0.73 & 0.89 & 0.73 & 0.85 & 0.78 & 0.317 & 0.795 \\
\hline W331545 & 10.2 & 6.0 & 1.5 & 4.5 & 0.73 & 0.88 & 0.97 & 0.87 & 0.61 & 0.340 & 0.840 \\
\hline P331040 & 7.0 & 5.0 & 1.0 & 4.0 & 0.73 & 0.94 & 0.69 & 0.84 & 0.55 & 0.219 & 0.771 \\
\hline P331050 & 7.3 & 6.0 & 1.0 & 5.0 & 0.69 & 0.93 & 0.91 & 0.81 & 0.52 & 0.251 & 0.802 \\
\hline P331525 & 9.8 & 4.0 & 1.5 & 2.5 & 1.00 & 0.89 & 0.36 & 0.98 & 0.72 & 0.228 & 0.806 \\
\hline P331535 & 10.0 & 5.0 & 1.5 & 3.5 & 0.73 & 0.89 & 0.70 & 0.85 & 0.58 & 0.228 & 0.771 \\
\hline P331545 & 10.2 & 6.0 & 1.5 & 4.5 & 0.69 & 0.88 & 0.93 & 0.81 & 0.57 & 0.265 & 0.801 \\
\hline P330535 & 3.9 & 4.0 & 0.5 & 3.5 & 1.00 & 1.00 & 0.34 & 0.95 & 0.59 & 0.188 & 0.799 \\
\hline P330545 & 4.1 & 5.0 & 0.5 & 4.5 & 0.73 & 0.99 & 0.68 & 0.82 & 0.52 & 0.212 & 0.772 \\
\hline P330555 & 4.3 & 6.0 & 0.5 & 5.5 & 0.70 & 0.99 & 0.88 & 0.80 & 0.49 & 0.238 & 0.799 \\
\hline W330535 & 3.8 & 4.0 & 0.5 & 3.5 & 1.00 & 1.00 & 0.36 & 0.95 & 0.63 & 0.213 & 0.806 \\
\hline W330545 & 4.1 & 5.0 & 0.5 & 4.5 & 0.73 & 1.00 & 0.68 & 0.86 & 0.54 & 0.231 & 0.783 \\
\hline W330555 & 4.3 & 6.0 & 0.5 & 5.5 & 0.73 & 0.99 & 0.92 & 0.86 & 0.53 & 0.307 & 0.837 \\
\hline W441040 & 12.8 & 5.0 & 1.0 & 4.0 & 0.85 & 0.84 & 0.53 & 0.89 & 0.49 & 0.167 & 0.755 \\
\hline P441040 & 12.4 & 5.0 & 1.0 & 4.0 & 1.00 & 0.85 & 0.36 & 0.85 & 1.00 & 0.268 & 0.794 \\
\hline
\end{tabular}




\section{REFERENCES}

[1] D. Lee et.al, Experimental validation of MCNP models for PINS shadow shield mockups, Idaho National Laboratory Report INL/EXT-19-54207 (2019)

[2] T. L. Saaty, The analytic hierarchy process, McGraw-Hill International, New York (1980)

[3] A.J. Caffrey, A.E. Egger, and B.C. Haddon, Gauss XI User's Manual, Idaho National Laboratory Report INL/EXT-11-24120-REV1 (2013)

[4] A. J. Caffrey, A. E. Egger, and K. M. Krebs, PINS Chemical Identification Software Guide, Idaho National Laboratory Report INL/LTD-13-30012 (2013) 